\title{
Lei sobre tratamento de câncer no SUS: análise dos dispositivos e perspectivas
}

Cancer Care Brazilian Act: analysis and perspectives

Descritores: câncer, tratamento; câncer, legislação; Sistema Único de Saúde Key-words: cancer, treatment; cancer, law; Brazilian Public Health System.

\section{Fábio de Barros Correia Gomes}

Médico, doutor em ciência política, consultor legislativo da Câmara dos Deputados e professor do mestrado profissional em Poder Legislativo da Câmara dos Deputados, Brasília, Brasil.

\section{Introdução}

Esse texto propõe-se a comentar sobre a Lei federal oㅜ 12.732, de 22 de novembro de 2012, que "dispõe sobre o primeiro tratamento de paciente com neoplasia maligna comprovada e estabelece prazo para seu início" no Sistema Único de Saúde (SUS).

Para tanto, são apresentados os dispositivos da referida lei, seguindo-se seções sobre: a análise de cada dispositivo (quando couber, segundo critérios de mérito técnico, necessidade legal, oportunidade no contexto da implementação do SUS e relevância para a saúde pública); a tramitação da proposição no Congresso Nacional, e, finalmente, as perspectivas associadas à vigência da Lei.

\section{Dispositivos da Lei 12.732, de 2012}

A Lei 12.732, de 2012, possui apenas cinco artigos. O primeiro estabelece que "o paciente com neoplasia maligna receberá, gratuitamente, no Sistema Único de Saúde (SUS), todos os tratamentos necessários, na forma desta Lei". O parágrafo único deste artigo indica que "a padronização de terapias do câncer, cirúrgicas e clínicas, deverá ser revista e republicada, e atualizada sempre que se fizer necessário, para se adequar ao conhecimento científico e à disponibilidade de novos tratamentos comprovados". 
De acordo com 0 art. 2º, "o paciente com neoplasia maligna tem direito de se submeter ao primeiro tratamento no Sistema Único de Saúde (SUS), no prazo de até 60 (sessenta) dias contados a partir do dia em que for firmado o diagnóstico em laudo patológico ou em prazo menor, conforme a necessidade terapêutica do caso registrada em prontuário único." O $\S 1^{0}$ indica que "para efeito do cumprimento do prazo estipulado no caput, considerar-se-á efetivamente iniciado o primeiro tratamento da neoplasia maligna, com a realização de terapia cirúrgica ou com o início de radioterapia ou de quimioterapia, conforme a necessidade terapêutica do caso". O § $2^{\circ}$ estabelece que "os pacientes acometidos por manifestações dolorosas consequentes de neoplasia maligna terão tratamento privilegiado e gratuito, quanto ao acesso às prescrições e dispensação de analgésicos opiáceos ou correlatos."

O art. 3 - determina que "o descumprimento desta Lei sujeitará os gestores direta e indiretamente responsáveis às penalidades administrativas"; 0 art. 4ㅜㅜ que "os Estados que apresentarem grandes espaços territoriais sem serviços especializados em oncologia deverão produzir planos regionais de instalação deles, para superar essa situação" e o art. 5ำ que a Lei "entra em vigor após decorridos 180 (cento e oitenta) dias de sua publicação oficial”.

\section{Análise dos dispositivos da Lei 12.732, de 2012}

$O$ art. $1^{\circ}$ menciona a questão da gratuidade do tratamento das neoplasias malignas no SUS, de mérito inegável, numa população em que a desigualdade econômica é estrutural. Aparentemente o dispositivo seria desnecessário do ponto de vista legal, pois a Lei Orgânica da Saúde (Lei $\mathrm{n}$ ำ 8.080, de 1990, já aborda esse tema genericamente). Contudo, o art. 43 da Lei Orgânica garante que "a gratuidade das ações e serviços de saúde fica preservada nos serviços públicos contratados", contudo ressalva "as cláusulas dos contratos ou convênios estabelecidos com as entidades privadas". Desse modo, a mais recente garantia da Lei 12.732 promoveria a gratuidade aos usuários do SUS com câncer em qualquer situação, o que é oportuno e relevante num contexto em que se observa expansão das interfaces entre o setor privado da saúde e o SUS. Contudo, é preciso questionar se essas garantias não deveriam abranger os demais usuários do SUS, com prognósticos tão graves quanto os de certos tipos de câncer. 
O parágrafo único deste artigo traz obrigação de revisão de padronizações de tratamento, tênues e subjetivas, tornando difícil a exigência de seu cumprimento; o que torna essa parte do dispositivo irrelevante, embora possa realçar a necessidade da revisão dos padrões, por ocasião da regulamentação infralegal.

$\mathrm{O}$ art. $2^{\circ}$ é o que ganhou maior destaque, pois estabelece um prazo (uma novidade no contexto da legislação sanitária) máximo de 60 dias para que o paciente com neoplasia maligna receba o primeiro tratamento no SUS. O prazo será contado a partir do dia em que for firmado o diagnóstico em laudo patológico. Foi previsto "prazo menor, conforme a necessidade terapêutica do caso registrada em prontuário único."

O mérito do dispositivo é elevado, pois esse tipo de patologia depende do diagnóstico precoce e do pronto tratamento para que a probabilidade de cura aumente. Quanto á necessidade legal, esta poderia ser questionada diante do direito à saúde já garantido pela Constituição Federal e também pela Lei Orgânica. A oportunidade e relevância do dispositivo são evidentes diante da situação atual do SUS, que devido a problemas de gestão e de subfinanciamento, não tem propiciado um tempo adequado de tratamento aos portadores de câncer no SUS. Nem mesmo os dados de tempo de espera estão disponíveis com a transparência necessária. O questionamento sobre a especificidade da norma, direcionada a determinada doença, pois muitos pacientes com outros tipos de patologia também enfrentam filas longas no SUS.

$O \S 1^{\circ}$ deste artigo identifica com clareza o significado de "primeiro tratamento", facilitando a exigência de sua execução e ampliando sua relevância. Já o $\S 2^{\circ}$ busca priorizar o tratamento da dor desses pacientes, de elevado mérito, mas também não seriam os casos de outros usuários com dor severa?

A previsão de penalidades administrativas aos gestores direta e indiretamente responsáveis (art. $3^{\circ}$ ) é um elemento que dá consequência às infrações à lei, sendo oportunas e relevantes, contudo, caso houvessem outros tipos de penalidades a lei poderia ser mais efetiva. A presença desse dispositivo salienta a necessidade de uma lei de responsabilidade sanitária. 
A previsão de elaboração de planos regionais pelos Estados que apresentarem grandes espaços territoriais sem serviços especializados em oncologia (art. $4^{\circ}$ ) é oportuna e relevante, mas também remete à questão da necessidade de um planejamento integrado de atenção à saúde, não apenas para os usuários com câncer.

Finalmente, os seis meses para entrada em vigência da nova Lei, demonstram a necessidade de tempo para a adequação dos serviços do SUS às "novas" obrigações.

\section{Tramitação da proposição no Congresso Nacional}

A observação da tramitação da proposição no Congresso Nacional fornece elementos relevantes a respeito da posição dos atores institucionais quanto à abrangência desejada da política pública adotada.

A proposição que deu início ao processo legislativo foi um projeto de lei ordinária do Senado Federal, o PLS 32, de 1997, de autoria do Senador Osmar Dias. Inicialmente a proposição dispunha sobre "o tratamento medicamentoso da dor em pacientes portadores de neoplasias comprovadas, por meio de entorpecentes". Teve relativamente rápida tramitação no Senado (apresentado em março, aprovado por decisão terminativa - apenas por meio das comissões - edespachado em novembro do mesmo ano para a Câmara. O texto enviado à Câmara tratava de um programa de controle da dor oncológica e não previa prazo de tratamento para o câncer.

$\mathrm{Na}$ Câmara, o projeto, com a denominação de PL 3.887/97 teve tramitação lenta. Foi aprovado na Comissão de Seguridade Social e Família (CSSF) em maio de 1999 e pela Comissão de Constituição e Justiça (CCJC) em junho de 2000. No plenário, foram apensados três projetos de lei ordinária, entre eles o PL 2.878/2011, de autoria da Deputada Carmen Zanotto, dispondo sobre o tratamento gratuito aos portadores de Neoplasias e estabelecendo prazo para início do tratamento (o máximo seria de 30 dias). A deputada citou dados de serviços de quimioterapia e radioterapia do SUS, indicando que o tempo médio de espera entre a data do diagnóstico e o início dos tratamentos foi de 76,3 e 113,4 dias, respectivamente. Também destacou que apenas $15,9 \%$ dos tratamentos de radioterapia e $35,6 \%$ dos de quimioterapia iniciaramse nos primeiros 30 dias. 
Segundo dados do Registro Hospitalar de Câncer (RHC) de São Paulo de 2009, o tempo médio de espera para o início dos tratamentos foi de 46,6 dias e apenas $52,4 \%$ dos tratamentos foram iniciados em 30 dias. Os dados do RHC do Instituto Nacional de Câncer de 2007, por sua vez, evidenciam que o tempo médio de espera para o início dos tratamentos foi de 70,3 dias e que, somente, $38,4 \%$ dos tratamentos foram iniciados nos primeiros 30 dias.

Em junho de 2012 foi aprovado requerimento de urgência de iniciativa de deputados e a proposição foi aprovada com o prazo modificado para 60 dias. 0 texto foi encaminhado ao Senado no mesmo mês, o qual aprovou a matéria em novembro de 2012, com a redação final da Câmara.

A tramitação evidencia que a matéria foi uma iniciativa de parlamentares e que a conformação final foi bem diferente e mais abrangente que a proposta inicial (o controle da dor, antes o foco, passou a ser abordado em um dos parágrafos de artigo da nova proposta). De fato, o projeto do Senado pode ter sido utilizado estrategicamente pelos deputados para acelerar a aprovação de um novo conteúdo, uma vez que a matéria já havia vencido uma fase de tramitação no Senado. Contudo, o prazo máximo de 30 dias para o início do tratamento, previsto na nova proposta, terminou sendo dobrado, o que, provavelmente, consistiu numa estratégia para reduzir resistências no Executivo, facilitando a aprovação da matéria.

\section{Perspectivas associadas à vigência da Lei}

O câncer, importante componente do grupo das doenças crônicas e degenerativas, tanto no que se refere à mortalidade, quanto à morbidade, tem ganhado destaque nas políticas de atenção à saúde do Brasil, um país que enfrenta a transição epidemiológica (com aumento da prevalência de doenças crônicas e degenerativas), e também a demográfica (com o envelhecimento da população). Nesse contexto, a produção de legislação abordando o tratamento do câncer demonstra sensibilidade do Congresso Nacional aos problemas que atingem a saúde da população. Contudo, cabe destacar, a esse respeito, a preocupação sobre a fragmentação da legislação sanitária. Seria oportuno tornar a legislação sanitária fragmentada a ponto de ter que considerar cada tipo de doença ou agravo? Não estaríamos a diluir o poder e legitimidade da Lei Orgânica de Saúde? 
O risco é a generalização dessa prática, com a "desmoralização" da Lei Orgânica da Saúde e verticalização da legislação e da política de saúde, com reflexos, inclusive, para a equidade em saúde; pois haveria incentivos para que o Executivo atuasse com maior ênfase para controlar agravos e doenças para os quais existissem leis específicas.

De todo modo, a legislação foi adotada e tem como justificativa maior a própria incapacidade de implantação do SUS do modo como foi previsto na Constituição Federal de 1988. Caso a lei estimule modelos para melhores práticas de gestão e de controle social no SUS (por exemplo, indicadores baseados em tempos de espera), poderão ocorrer ganhos sistêmicos, mas é preciso vigilância para evitar mais iniquidades entre os usuários.

Uma grande fonte de preocupação é que a lei aborda prazo de tratamento após o diagnóstico, contudo se o acesso aos meios diagnósticos continuarem precários, o efeito benéfico da lei será reduzido. Segundo o Ministério da Saúde, $45 \%$ dos pacientes com câncer têm o primeiro atendimento já quando a doença está em estágio avançado (níveis 3 ou 4). Mais uma vez coloca-se a questão sistêmica, da necessidade da melhoria homogênea do SUS, principalmente da atenção básica, para que diagnósticos precoces sejam realizados.

O próprio registro do diagnóstico para fins de contagem do prazo é uma questão relevante, que deveria proteger 0 usuário por ocasião da regulamentação, pois se este obtiver um laudo de exame em determinada data, mas só conseguir consulta (em que o laudo seria registrado no prontuário) meses depois, a situação prejudicaria o usuário.

A esse respeito, a portaria do Ministério da Saúde $n^{0} 876$, de 16 de maio de 2013, que regulamenta a lei em análise, estabelece que "o prazo de 60 (sessenta) dias fixado no art. 20 da Lei oㅜ 12.732, de 2012, para fins do primeiro tratamento cirúrgico ou quimioterápico ou radioterápico do paciente no SUS, contar-se-á a partir do registro do diagnóstico no prontuário do paciente" (art. $3^{\circ}$ ). Essa regulamentação contraria a Lei, a qual explicitamente determina que o prazo seja contado "a partir do dia em que for firmado o diagnóstico em laudo patológico". Isso pode prolongar artificialmente o prazo legal de tratamento. A referida portaria ainda "exclui" certas neoplasias do prazo de 60 dias, o que não está previsto na Lei, contrariando a hierarquia das normas. 
Uma vez realizado o diagnóstico, toda uma rede de atenção especializada precisará ser mobilizada, e para isso são necessários recursos materiais e humanos. Se a situação de subfinanciamento do SUS já ocorre atualmente, é plausível supor que uma eventual melhoria de serviços para o tratamento do câncer possa ocorrer por ajustes na gestão, mas também às custas de redução de recursos em outras áreas da saúde, caso não ocorra aporte de recursos "novos". Assim, as futuras leis orçamentárias precisam refletir o suporte ao cumprimento das obrigações de prazo de tratamento, sem prejudicar outros setores da saúde, e mais que isso, prever melhorias nos diversos níveis de atenção do SUS.

Também saliento a opção final do prazo máximo para iniciar o tratamento de 60 dias e não o inicialmente desejado na proposta da Câmara (de 30 dias). Dados do Ministério da Saúde indicam que 78\% dos casos de câncer em estágio inicial já tinham tratamento iniciado em até 60 dias antes da adoção da lei. Talvez a meta tenha sido colocada num patamar que represente menor desafio aos gestores, contudo uma meta equitativa deveria focar as reais necessidades dos usuários.

Finalmente, destaco que a Lei 12.732, de 2012, já em vigor, soma-se aos dispositivos já disponíveis na legislação, para que eventuais descumprimentos sejam abordados judicialmente. Considerando que a demora no tratamento do câncer representa uma situação de profunda iniquidade, esta não se constitui num mero instrumento para "judicializar" a questão atendimento no SUS, mas uma tentativa de corrigir violações extremas ao direito constitucional à saúde.

Diante das potenciais vantagens e também dos riscos da nova lei (como também da regulamentação infralegal) para os usuários do SUS, cabe o adequado monitoramento de sua implantação, particularmente dos tempos de espera para tratamento, e atenção para os desdobramentos sistêmicos, com ampla divulgação para o controle social. 